\title{
Centering Parenting: procesevaluatie van een cultuursensitieve variant voor moeders en kinderen tussen 0 en 4 jaar oud in een asielzoekerscentrum
}

\author{
I. Linden · N. M. C. van Kesteren · P. de Jong · F. Pannebakker
}

Published online: 27 July 2020

(C) Bohn Stafleu van Loghum is een imprint van Springer Media B.V., onderdeel van Springer Nature 2020

\begin{abstract}
Samenvatting Inleiding: Ouders in asielzoekerscentra (azc) voelen zich vaak onvoldoende ondersteund in hun opvoedtaak en het huidige ondersteuningsaanbod van de jeugdgezondheidszorg (JGZ) sluit onvoldoende aan bij hun belevingswereld en behoeften. Centering Parenting $(\mathrm{CPa})$ is een groepsaanpak van de JGZ die veel ruimte biedt voor preventie en sociale steun tracht te bevorderen. In een pilotonderzoek in een azc in Katwijk is nagegaan of uitvoering van een cultuursensitieve variant van $\mathrm{CPa}$ bij moeders van baby's en peuters haalbaar is.

Methode: Er werd een procesevaluatie uitgevoerd, met als doel de compleetheid, programma-integriteit en waardering onder deelnemende moeders en JGZprofessionals te onderzoeken. Dit gebeurde aan de hand van logboeken, observaties en semigestructureerde interviews met moeders en JGZ-professionals. Resultaten: De resultaten betreffende de programmaintegriteit waren positief. Zo bleek het mogelijk om de principes en strategieën van $\mathrm{CPa}$ grotendeels intact te houden. De deelnemende moeders en de JGZprofessionals ervaarden de $\mathrm{CPa}$-sessies eveneens als positief. De compleetheid van de uitvoering van de cultuursensitieve CPa viel echter tegen. Van de acht sessies werden er zeven uitgevoerd. Van de compo-
\end{abstract}

\footnotetext{
I. Linden

Afdeling Psychiatrie en Neuropsychologie, School for Mental Health and NeuroScience (MHeNS), Maastricht University, Maastricht, Nederland

N. M. C. van Kesteren $(\bowtie) \cdot$ F. Pannebakker

Expertisegroep Child Health, TNO (Nederlandse Organisatie voor toegepast-natuurwetenschappelijk onderzoek), Leiden, Nederland

nicole.vankesteren@tno.nl

P. de Jong

Jeugdgezondheidszorg, GGD Hollands Midden, AZC

Katwijk/Rijswijk, Nederland
}

nenten en thema's werden er in de babygroep respectievelijk $80 \%$ en $45 \%$ behandeld en in de peutergroep $50 \%$ en $28 \%$.

Conclusie: Het invoeren van de cultuursensitieve variant van $\mathrm{CPa}$ gaat gepaard met de nodige uitdagingen, maar lijkt haalbaar en vormt een goede aanvulling op de huidige werkwijze. Aanbevolen wordt om bij de groepssamenstelling rekening te houden met de culturele achtergrond van de moeders om groepsinteractie te bevorderen. Tevens is het van belang om realistische verwachtingen te hebben van het aantal thema's dat per sessie behandeld kan worden.

Trefwoorden Centering Parenting $\cdot$ Cultuursensitief - Kinderen 0 tot 4 jaar - Procesevaluatie . Asielzoekerscentra

\section{Inleiding}

In januari 2019 woonden er zo'n 2000 kinderen tussen de 0 en 4 jaar in een opvanglocatie van het Centraal Orgaan opvang asielzoekers [1]. Kinderen in een asielzoekerscentrum (azc) hebben vergeleken met andere kinderen in Nederland meer lichamelijke en psychische klachten [2-4]. Ouders van asielzoekerskinderen staan bovendien zelf veelal onder grote stress, lopen het risico op isolement, en kampen vaak met lichamelijke en psychische klachten [5]. Dat maakt het voor ouders extra lastig een optimaal pedagogisch klimaat te scheppen [6]. Ouders in opvanglocaties voelen zich vaak onvoldoende ondersteund in hun opvoedtaak en het huidige ondersteuningsaanbod sluit onvoldoende aan bij de belevingswereld en behoefte van deze doelgroep [7].

Centering Parenting $(\mathrm{CPa})$ is een groepsaanpak van de jeugdgezondheidszorg (JGZ) gericht op moeders en jonge kinderen. De aanpak biedt veel ruimte voor preventie en zorg, en tracht sociale steun te bevorderen 
[8]. Doelen van CPa betreffen: a) het bevorderen van het gezond en veilig opgroeien van kinderen; b) het versterken van de eigen kracht (empowerment) van moeders; en c) het creëren van een community voor moeders en kinderen waarin zij zich ondersteund voelen en waarbinnen uitwisseling en verandering mogelijk worden gemaakt [8]. Sinds 2014 wordt CPa aangeboden aan moeders van pasgeboren kinderen in drie JGZ-organisaties in Nederland. Moeders die deelnemen aan CPa zijn tevredener over de zorg en ervaren meer opvoedcompetentie [8]. Tot dusver is nog geen ervaring opgedaan met de groepsaanpak in azc's.

Om CPa geschikt te maken voor ouders van asielzoekerskinderen werd de aanpak, op basis van de behoeften van de doelgroep, cultuursensitief gemaakt [9]. De cultuursensitieve variant werd vervolgens in een pilot onderzocht in azc Katwijk om meer inzicht te krijgen in de haalbaarheid. Met behulp van een procesevaluatie werden de compleetheid, programma-integriteit en waardering van de cultuursensitieve variant onder deelnemende moeders en JGZ-professionals onderzocht.

\section{Methode}

Het pilotonderzoek werd tussen september en december 2018 uitgevoerd in azc Katwijk.

\section{Setting}

Het azc Katwijk valt in het werkgebied van de GGD Hollands Midden. Dit azc is sinds 2011 in gebruik als gezinslocatie en biedt opvang aan uitgeprocedeerde gezinnen met minderjarige kinderen, die na de wette- lijke vertrektermijn in Nederland verblijven. Azc Katwijk heeft een opvangcapaciteit van 570 plaatsen.

Binnen de gezinslocatie Katwijk werden twee CPagroepen gevormd: een babygroep en een peutergroep. Aan de babygroep namen acht moeders deel, afkomstig uit China, Eritrea, Irak, Mongolië en Oekraïne. De Nederlandse/Engelse taalvaardigheid van deze moeders was matig tot zeer slecht. De leeftijd van de baby's was gemiddeld 11,4 maanden $(s d=3,1)$. Vier moeders, afkomstig uit Angola, Congo en Eritrea, namen deel aan de peutergroep. Hun Nederlandse/ Engelse taalvaardigheid varieerde van goed tot matig. De leeftijd van de peuters was gemiddeld 34 maanden $(s d=3,4)$. Beide groepen werden begeleid door twee JGZ-professionals van GGD Hollands Midden.

\section{Cultuursensitieve aanpassing $\mathrm{CPa}$}

$\mathrm{CPa}$ werd in samenwerking met Stichting Centering en op basis van een systematische benadering cultuursensitief gemaakt voor de doelgroep in deze pilot [10]. Cultuursensitief maken houdt in dat de interventie wordt afgestemd op de behoeften van de doelgroep met een andere culturele achtergrond dan de Nederlandse, waarbij ruimte is voor een eigen kijk op gezond en veilig opgroeien en ouderschap [11]. In dit kader werden achttien moeders uit de familielocatie Katwijk geïnterviewd over hun behoeften en ervaringen met betrekking tot opvoeden. Moeders dachten ook mee over het werven van andere moeders voor de groepssessies. Op basis hiervan werden de inhoud van de sessies, de werkvormen en de wervingsstrategie vormgegeven en aangepast (zie tab. 1 voor een overzicht). De sessies werden ondersteund met een

Tabel 1 Doelen, werkprincipes en strategieën van Centering Parenting (CPa)

\begin{tabular}{|c|c|c|c|}
\hline Doelen & Werkprincipes & Strategieën & Cultureel-sensitieve aanpassingen \\
\hline $\begin{array}{l}\text { Het bevorderen van ge- } \\
\text { zond en veilig opgroeien } \\
\text { van kinderen }\end{array}$ & $\begin{array}{l}\text { 1. Preventieve } \\
\text { voorlichting } \\
\text { 2. Regelma- } \\
\text { tige medische } \\
\text { controle }\end{array}$ & $\begin{array}{l}\text { 1. Toegankelijke en relevante voorlich- } \\
\text { ting aan de hand van groepsinteractie } \\
\text { 2. Ouderboek als naslagwerk en } \\
\text { hulpmiddel bij veel voorkomende } \\
\text { opvoedvragen }\end{array}$ & $\begin{array}{l}\text { 1. De preventieve voorlichting is in het Engels en Nederlands gegeven } \\
\text { 2. De inhoud van de preventieve voorlichting is aangepast aan de be- } \\
\text { hoeften van moeders, onder andere thema's als voeding en slapen zijn } \\
\text { aangepast aan uitdagingen die de moeders tegen komen in het azc, } \\
\text { thema's over meertaligheid en culturele opvattingen zijn opgenomen } \\
\text { in het programma. Er wordt ook aandacht besteed aan bijkomende } \\
\text { stressfactoren in het leven in een azc } \\
\text { 3. Het ouderboek is in samenwerking met een illustrator gevisuali- } \\
\text { seerd }\end{array}$ \\
\hline $\begin{array}{l}\text { Het versterken van de } \\
\text { eigen kracht (empower- } \\
\text { ment) van moeders, zodat } \\
\text { ze in staat worden gesteld } \\
\text { zelf beslissingen te ne- } \\
\text { men over gezond en veilig } \\
\text { opgroeien }\end{array}$ & $\begin{array}{l}\text { 1. Moeders } \\
\text { actief betrekken } \\
\text { bij de medische } \\
\text { controle } \\
\text { 2. Interactieve } \\
\text { voorlichting }\end{array}$ & $\begin{array}{l}\text { 1. Moeders zelf het kind laten meten } \\
\text { en wegen } \\
\text { 2. Moeders zelf de medische gege- } \\
\text { vens van het kind laten opschrijven } \\
\text { 3. Mogelijkheid geven tot actieve } \\
\text { deelname aan de voorlichting } \\
\text { 4. JGZ-professionals geven weinig tot } \\
\text { geen informatie op een didactische } \\
\text { manier }\end{array}$ & $\begin{array}{l}\text { 1. Er zijn interactieve werkvormen ontwikkeld aan de hand van afbeel- } \\
\text { dingen om een eventuele taalbarrière te overbruggen }\end{array}$ \\
\hline $\begin{array}{l}\text { Het creëren van een com- } \\
\text { munity voor moeders en } \\
\text { kinderen waarbinnen ze } \\
\text { zich ondersteund voelen } \\
\text { en waarbinnen uitwis- } \\
\text { seling en verandering } \\
\text { mogelijk wordt gemaakt }\end{array}$ & $\begin{array}{l}\text { 1. Preventieve } \\
\text { voorlichting } \\
\text { in een groep } \\
\text { geven }\end{array}$ & $\begin{array}{l}\text { 1. Informeel contact tussen moeders } \\
\text { tot stand brengen door het delen van } \\
\text { ervaringen/het zoeken naar overeen- } \\
\text { komsten } \\
\text { 2. Een gevoel van geborgenheid en } \\
\text { veiligheid creëren }\end{array}$ & $\begin{array}{l}\text { 1. Het tijdstip van de groepsbijeenkomst is aangepast aan de gang van } \\
\text { zaken in een azc om de opkomst zo groot mogelijk te maken } \\
\text { 2. De groepen zijn samengesteld op basis van het taalvaardigheidsni- } \\
\text { veau van de moeders } \\
\text { 3. De bijeenkomst wordt gegeven in een ruimte die zo is ingericht dat } \\
\text { moeders en kinderen zich op hun gemak voelen }\end{array}$ \\
\hline
\end{tabular}




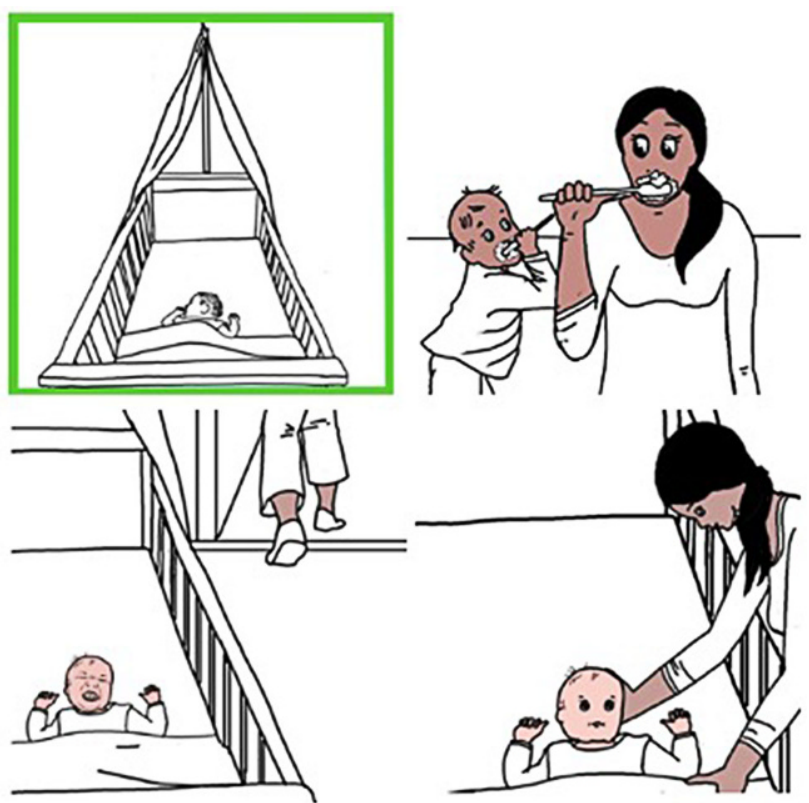

Figuur 1 Voorbeelden van cultuursensitieve afbeeldingen opgenomen in het ouderboek

ouderboek en daarvoor speciaal ontwikkelde cultuursensitieve afbeeldingen (zie fig. 1).

Er werden twee versies van $\mathrm{CPa}$ ontwikkeld: een versie voor moeders met kinderen tussen 0 en 2 jaar (de babygroep) en een versie voor moeders met kinderen tussen 2 en 4 jaar (de peutergroep) (zie tab. 2 voor de componenten en thema's van beide versies). $\mathrm{CPa}$ werd aangeboden in plaats van de gebruikelijke individuele JGZ-contactmomenten. Beide versies bestonden uit maandelijkse groepssessies van 2 uur die gedurende 4 maanden door JGZ-professionals gegeven werden. In beide groepen werden in alle sessies dezelfde thema's behandeld, maar deze werden aangepast aan de baby- of peuterfase. Iedere sessie startte met een kort medisch onderzoek en het meten en wegen van twee kinderen, in samenwerking met de moeders. Dit medisch onderzoek diende als vervanging voor de reguliere medische controle bij de JGZ. Kinderen werden op basis van het reguliere zorgschema geselecteerd. Een medische controle duurde minimaal 15 minuten. Het onderzoeken van twee kinderen per sessie (een half uur) was daarom het maximum voor de JGZ-professionals. De resterende tijd werd ingevuld met het geven van preventieve voorlichting aan de hand van interactieve werkvormen. Ter ondersteuning van de sessies kregen alle moeders een 'ouderboek', waarin de belangrijkste informatie uit de sessies visueel werd uitgelegd.

\section{Componenten van de procesevaluatie}

Met de procesevaluatie werden de compleetheid, programma-integriteit en waardering onderzocht. Onder compleetheid wordt dat deel van de interventiecomponenten en -activiteiten verstaan dat daadwerkelijk wordt uitgevoerd, terwijl programma-integriteit een indicatie geeft van de mate waarin een interventie volgens de vastgestelde uitgangspunten en richtlijnen geïmplementeerd wordt [12].

De compleetheid werd in kaart gebracht via observaties van alle sessies en logboeken. Er werd een gestructureerd observatieschema opgesteld op basis van de methoden en strategieën van het reguliere CPa-programma [13]. Met het observatieschema werd geregistreerd hoeveel van de: 1) sessies $(n=8)$; 2) behandelde componenten (overkoepelende onderdelen, bijvoorbeeld 'voeding') ( $n=10)$ en 3) thema's (subonderdelen, bijvoorbeeld 'veilig koken in het azc') $(n=40)$ werden uitgevoerd. Na iedere sessie vulden de JGZ-professionals een logboek in waarin zij aangaven hoeveel moeders aanwezig waren, welke medische handelingen bij hoeveel kinderen werden uitgevoerd, welke onderwerpen behandeld werden en welke werkvormen werden gebruikt.

Om de programma-integriteit in kaart te brengen werd ook gebruikgemaakt van de observaties en logboeken van alle gegeven sessies. Geobserveerd werd in hoeverre CPa-werkprincipes en -strategieën (zie tab. 1) gebruikt werden en bij de deelnemers aansloegen. Als onderdeel van de logboeken werd na afloop van de sessies aan de JGZ-professionals een aantal procesvragen gesteld. Deze vragen hadden betrekking op de geschiktheid van de groepsruimte, de mate waarin de moeders actief participeerden bij de medische controle en tijdens de sessies, de voorbereidingstijd en eventuele verbeterpunten.

De waardering onder moeders en JGZ-professionals werd in kaart gebracht met semigestructureerde interviews. De interviews werden een tot drie weken na afloop van de laatste sessie afgenomen en vonden plaats onder negen van de twaalf moeders die deelnamen aan de baby- en peutergroep. De moeders werd gevraagd hoe ze de sessies in het algemeen beoordeelden, hoe relevant ze de inhoud van de sessies vonden en wat hun mening was over het contact met de JGZ-professionals en het groepsproces. Daarnaast werd moeders gevraagd een indicatie te geven van hun contact met de andere moeders uit de groep buiten de groepssessies om en hun bereidheid om andere moeders indien nodig te helpen (sociale steun). De interviews duurden gemiddeld 30 minuten en vonden plaats op het azc Katwijk. Zo nodig werd gebruikgemaakt van een telefonische tolk. Voorafgaand aan het interview ondertekenden alle deelnemers een informed consent-formulier. De deelnemers ontvingen een cadeaubon van $€ 10$ voor de deelname aan het interview.

$\mathrm{Na}$ afloop van de laatste sessie nam de onderzoeker in aanvulling hierop met een van de twee JGZprofessionals die de sessies begeleidden een semigestructureerd interview af. Doel van het interview was om de ervaringen met $\mathrm{CPa}$ voor de huidige doelgroep in kaart te brengen, evenals bevorderende en belemmerende factoren van implementatie. 
Tabel 2 Componenten en thema's in de cultuursensitieve CPa-variant en uitvoering hiervan in het pilotonderzoek

\begin{tabular}{|c|c|c|c|c|c|c|}
\hline \multirow[t]{2}{*}{ Sessie } & \multirow[t]{2}{*}{ Componenten } & \multicolumn{2}{|l|}{ Uitvoering } & \multirow[t]{2}{*}{ Thema's } & \multicolumn{2}{|l|}{ Uitvoering } \\
\hline & & Babygroep & Peutergroep & & Babygroep & Peutergroep \\
\hline \multirow[t]{10}{*}{1} & \multirow[t]{5}{*}{ Voeding } & $x$ & $\mathrm{x}$ & Veilig koken in het azc & $\mathrm{X}$ & \\
\hline & & & & Koken met een klein budget & & \\
\hline & & & & Culturele opvattingen over eten & & $\mathrm{x}$ \\
\hline & & & & Gezonde voeding en eetpatroon & $x^{a}$ & $x^{a}$ \\
\hline & & & & Voorkomen overgewicht & & \\
\hline & \multirow[t]{4}{*}{ Slapen } & $\mathrm{X}$ & $\mathrm{x}$ & Culturele opvattingen over slapen & & $\mathrm{x}$ \\
\hline & & & & Hoeveel moet mijn kind slapen? & & \\
\hline & & & & Veilig slapen & $x^{a}$ & $x^{a}$ \\
\hline & & & & Eigen slaapritueel & & $x^{a}$ \\
\hline & Veiligheid & & & Veiligheid rondom de woning binnen het azc & & \\
\hline \multirow[t]{10}{*}{2} & \multirow[t]{3}{*}{ Taal } & $\mathrm{x}$ & & Gevolgen van meertaligheid bij kinderen & $x^{a}$ & \\
\hline & & & & Belang van praten tegen je kind & $x^{a}$ & \\
\hline & & & & Nut van zingen voor/met je kind & $x^{a}$ & \\
\hline & \multirow{2}{*}{$\begin{array}{l}\text { Taalont- } \\
\text { wikkeling }\end{array}$} & $\mathrm{x}$ & & Culturele opvattingen over taal/taalontwikkeling & $\mathrm{x}$ & \\
\hline & & & & Gebruik van tablet voor taalontwikkeling & $x^{a}$ & \\
\hline & \multirow[t]{5}{*}{ Spelen } & $x$ & & Contact maken kind-moeder & $x^{a}$ & \\
\hline & & & & Contact maken moeder-kind & $x^{a}$ & \\
\hline & & & & Wat doet een kind als de moeder niet reageert? & $x^{a}$ & \\
\hline & & & & Culturele opvattingen over spelen & & \\
\hline & & & & $\begin{array}{l}\text { Wat kan een kind op welke leeftijd, en welk speelgoed past } \\
\text { daarbij? }\end{array}$ & $x^{a}$ & \\
\hline \multirow[t]{11}{*}{3} & \multirow[t]{7}{*}{ Ouderschap } & $\mathrm{x}$ & $\mathrm{x}$ & Positieve aspecten van je eigen opvoeding & & \\
\hline & & & & Wat wil je meegeven aan je kind? & & \\
\hline & & & & Goed ouderschap & & \\
\hline & & & & Verschillen in ouderschap & & \\
\hline & & & & Verhaal van de ouder als vluchteling & $x$ & \\
\hline & & & & Stress/spanning/depressie & $x^{a}$ & $\mathrm{x}$ \\
\hline & & & & Hoe kunnen moeders elkaar ondersteunen? & $\mathrm{x}$ & $x^{a}$ \\
\hline & \multirow{4}{*}{$\begin{array}{l}\text { Ontwikkeling } \\
\text { kind }\end{array}$} & & & Fasen in de ontwikkeling van je kind & & \\
\hline & & & & Waar zit jouw kind qua ontwikkeling? & & \\
\hline & & & & Verschillen in de ontwikkeling van kinderen & & \\
\hline & & & & Peuterpuberteit ${ }^{b}$ & & \\
\hline \multirow[t]{10}{*}{4} & \multirow[t]{7}{*}{ Opvoeden } & $\mathrm{x}$ & $\mathrm{x}$ & Eigen gedrag als kind & $x^{a}$ & $x^{a}$ \\
\hline & & & & Gedrag van je eigen kind & $x^{a}$ & $x^{a}$ \\
\hline & & & & Opvoedstijlen & & $\mathrm{X}$ \\
\hline & & & & Voor-en-nadelen opvoedstijlen & & \\
\hline & & & & Eigen opvoedstijl & & \\
\hline & & & & Gewenste opvoedstijl (en hoe dat te bereiken) & & \\
\hline & & & & Relatie met opvoeden (en hoe dat beter kan) & & \\
\hline & \multirow{3}{*}{$\begin{array}{l}\text { Regels } \\
\text { hanteren }\end{array}$} & $\mathrm{x}$ & $x$ & Consequent zijn & & \\
\hline & & & & Mopperen & & \\
\hline & & & & Niet op één lijn zitten & $\mathrm{x}$ & $x^{a}$ \\
\hline
\end{tabular}

\section{Gegevensanalyse}

De interviews werden opgenomen en getranscribeerd. Vervolgens maakte een van de onderzoekers een thematische analyse van de kwalitatieve gegevens uit de logboeken, observatieschema's en interviews.

\section{Resultaten}

\section{Compleetheid}

In de babygroep werden alle geplande sessies uitgevoerd. In de peutergroep kwam één sessie te verval- 
len door een te lage deelnemersopkomst. Hoewel alle sessies ongeveer zolang duurden als voorgeschreven (circa 2 uur), werden in beide groepen niet alle componenten en thema's behandeld. In de babygroep werden 8 van de 10 (80\%) van de voorgeschreven componenten behandeld en daarbinnen 18 van de 40 thema's (45\%). In de peutergroep werden 5 van de $10(50 \%)$ van de componenten behandeld en daarbinnen 11 van de 40 thema's (28\%) (zie tab. 2). Redenen waren uitval van één sessie, de ervaren taalbarrière en tijdnood. Verder vond er iedere sessie, zoals voorgeschreven, bij twee kinderen een medische controle plaats, zowel in de baby- als in de peutergroep.

\section{Programma-integriteit}

Uit de observaties bleek dat alle sessies grotendeels uitgevoerd zijn aan de hand van de principes en strategieën van CPa (zie tab. 1). JGZ-professionals maakten ten eerste gebruik van interactieve groepsgesprekken aan de hand waarvan preventieve voorlichting werd gegeven. Ten tweede gebruikten ze een faciliterende gesprekscyclus (een systematische manier om deelnemers te stimuleren actief deel te nemen aan een gesprek) om groepsinteractie en discussie binnen de groep te stimuleren. Ook probeerden JGZ-professionals groepsinteractie te stimuleren door: 1) het stellen van vragen en het geven van de uitleg in zowel het Nederlands als Engels; en 2) het uitgebreid bespreken van onderwerpen die de deelnemers inbrachten. Op de derde plaats betrokken JGZ-professionals de moeders actief bij de medische controle van hun kind. Ten vierde probeerden JGZ-professionals sociale steun te bevorderen door moeders een kans te bieden voor informeel contact aan het begin van de sessie, tijdens de pauze en buiten de sessies om.

\section{Waardering}

Uit de interviews met de moeders kwam naar voren dat zij de groepssessies waardeerden. Ze gaven aan het prettig te vinden om met elkaar in contact te komen en tegelijkertijd nieuwe kennis op te doen over de zorg en opvoeding voor hun kinderen. Daarnaast gaf een meerderheid van de moeders uit zowel de baby- als de peutergroep aan vaak alleen thuis te zitten en de CPa-sessie als een welkome onderbreking te zien van de dagelijkse gang van zaken. Ook waren ze positief over de inhoud van de sessies: bijna alle moeders gaven aan de behandelde thema's relevant te vinden. De taalbarrière bleek echter lastig. De helft van de moeders uit de babygroep gaf aan het moeilijk te vinden de inhoudelijke voorlichting van de professionals te volgen. Wel hielpen moeders met eenzelfde culturele achtergrond elkaar tijdens de sessies om de voorlichting te begrijpen. De ervaren taalbarrière bemoeilijkte eveneens het uitwisselen van ervaringen met andere moeders. Buiten de sessies om hadden de moeders weinig contact met elkaar, terwijl de meerderheid aangaf een dergelijk contact wel op prijs te stellen. De waardering voor de JGZ-professionals onder de moeders was groot, waarbij vooral de aandacht en zorgzaamheid werden genoemd. Ten slotte zei de meerderheid van de moeders het ouderboek en de cultuursensitieve afbeeldingen daarin behulpzaam te vinden. Het ouderboek werd geraadpleegd als ze tijdens de sessie iets niet begrepen of thuis gebruikt als naslagwerk.

Uit het interview en de korte evaluaties na afloop van iedere sessie bleek dat beide JGZ-professionals de $\mathrm{CPa}$-sessies als positief hebben ervaren. Ze noemden de extra tijd om meer preventieve zorg te bieden en het feit dat de moeders zichtbaar blij waren om samen te zijn. Wel werd het werven van de moeders en het begeleiden van de sessies als erg intensief ervaren. De professionals ervaarden de taalvaardigheid van de moeders ook als belemmerend. Dit gold vooral voor de babygroep, waarin de taalvaardigheid van de moeders over het algemeen laag was. Daardoor verliepen (delen van) de sessies over onderwerpen waarbij meer uitleg nodig was soms moeilijk. Het kostte door de beperkte taalvaardigheid van de moeders relatief veel moeite om alle moeders actief te betrekken. In aanvulling hierop gaven de professionals aan weinig zicht te hebben op hoeveel de deelnemers tijdens de sessies precies begrepen hadden, hoewel ze vermoedden dat de moeders een relatief grote 'passieve' woordenschat van de Nederlandse taal hadden. Het begeleiden van de sessies met behulp van afbeeldingen ervaarden de professionals als positief.

\section{Beschouwing}

Doel van dit onderzoek was om in een pilot een cultuursensitieve variant van $\mathrm{CPa}$ voor moeders verblijvend in het azc Katwijk uit te testen, om zo inzicht te krijgen in de haalbaarheid ervan. Daartoe werd een procesevaluatie uitgevoerd waarin de compleetheid van, de programma-integriteit van en waardering voor $\mathrm{CPa}$ onder deelnemende moeders en JGZprofessionals in kaart werden gebracht.

Uit de resultaten bleek ten eerste dat 7 van de 8 sessies werden uitgevoerd. Ten tweede werd slechts een deel van de componenten (babygroep: $80 \%$, peutergroep: $50 \%$ ) en de thema's (babygroep: $45 \%$, peutergroep: $28 \%$ ) behandeld. De ervaren taalbarrière speelt hierin een belangrijke rol. Moeders met een lagere taalvaardigheid hadden meer moeite om de voorlichting inhoudelijk te volgen en waren in mindere mate in staat om ervaringen uit te wisselen met andere moeders. Er was daarom per onderdeel meer tijd nodig dan tevoren was ingeschat. Wanneer de culturele achtergrond van de deelnemers homogener zou zijn, zouden de problemen als gevolg van een taalbarrière waarschijnlijk kleiner zijn, terwijl de mogelijkheid tot actieve participatie zou toenemen. Het vinden van herkenning bij andere deelnemers en het delen van dezelfde normen en waarden vergroot na- 
melijk de impact van een interventie [14]. JGZ-professionals gaven ook aan dat het gebruik van cultuursensitieve afbeeldingen hielp om de ervaren taalbarrière te slechten. Dit komt overeen met onderzoek van Bauman, waaruit blijkt dat het cultuursensitief maken van interventiemateriaal de acceptie en het begrip van interventiemateriaal vergroot [15]. Naast de taalbarrière hebben mogelijk (te) hoge verwachtingen vooraf een rol gespeeld bij de tegenvallende resultaten met betrekking tot de compleetheid. Het bleek niet haalbaar alle componenten en thema's uit te voeren.

Wat betreft de programma-integriteit bleek het mogelijk om de CPa-principes en -strategieën grotendeels te handhaven. Desondanks bleek de mate van sociaal contact en steun tussen deelnemers buiten de sessies om laag. Moeders die in een azc verblijven kampen met veel onzekerheden en lichamelijke en psychische klachten [5]. Samen met een taalbarrière heeft dit mogelijk gezorgd voor een beperking van het sociale contact tussen deelnemers buiten de sessies om.

De moeders en de JGZ-professionals bleken de sessies te waarderen. De moeders beoordeelden de inhoud als positief en zagen de sessies als een welkome onderbreking van de dagelijkse gang van zaken. JGZprofessionals waren vooral positief over de mogelijkheid om meer preventieve zorg te bieden.

Samenvattend, hoewel niet alle componenten en thema's uitgevoerd werden en de sociale contacten tussen deelnemers nog beperkt waren, bleken de $\mathrm{CPa}$ principes en -strategieën in deze doelgroep bruikbaar en ervaarden de moeders en JGZ-professionals de sessies als positief.

Het onderzoek kent enkele beperkingen. De belangrijkste betreft het kleinschalige karakter. Om betrouwbare uitspraken te kunnen doen over de haalbaarheid van een cultuursensitieve variant van CPa in een doelgroep van asielzoekers zal de procesevaluatie op grotere schaal moeten worden uitgevoerd. Verder speelde de ervaren taalbarrière niet alleen een rol bij het uitvoeren van de sessies, maar ook bij het interviewen van de deelnemende moeders. Er werd weliswaar een tolk ingezet, maar het blijft altijd mogelijk dat uitspraken van de moeders foutief zijn geïnterpreteerd. Bovendien werden de interviews afgenomen door de onderzoeker die ook de sessies observeerde. Deelnemers hebben hierdoor mogelijk sociaal wenselijke antwoorden gegeven.

\section{Conclusie}

Op basis van de eerste resultaten lijkt de cultuursensitieve variant van CPa haalbaar en een goede aanvulling op de reguliere JGZ voor uitgeprocedeerde asielzoekers. Implementatie gaat gepaard met uitdagingen, maar met de nodige aanpassingen zijn de principes en strategieën van CPa bij deze doelgroep goed te handhaven. Daarbij is het wel van groot belang om realistische verwachtingen te koesteren wat betreft het aantal componenten en thema's dat in de sessies kan worden behandeld.

Dankbetuiging Dit onderzoek werd mogelijk gemaakt door een subsidie van ZonMw (projectnummer 736300001). We bedanken Jolanda de Jong (GGD Hollands Midden), Stichting Centering Nederland en stagiaire Janneke Vermeulen voor hun inzet en betrokkenheid. Ook bedanken we alle moeders uit het asielzoekerscentrum in Katwijk die betrokken zijn geweest bij dit onderzoek.

\section{Literatuur}

1. COA. Personen in de opvang uitgesplitst naar leeftijd en land van herkomst. 2019. https://www. coa.nl/nl/over-coa/bezetting/personen-in-de-opvanguitgesplitst-naar-leeftijd-en-land-van-herkomst. Geraadpleegd op: 10 nov 2019.

2. Kloosterboer C. Kind in het centrum: kinderrechten in asielzoekerscentra. Den Haag: Unicef Nederland; 2009.

3. Werkgroep Kind in Azc. Het is hier in één woord gewoon ... stom!' Onderzoeknaar hetwelzijn en perspectief van kinderen en jongeren in gezinslocaties. 2014. http://www.kindin-azc.nl/docs/rapport_gezinslocaties.pdf. Geraadpleegd op: 10 nov 2019.

4. Spierenburg K, Davis O, Pronk W, Baars B van. Preventieproject asielzoekers Almere. Deel 1: probleemanalyse en interventiekeuze. Almere: Projectgroep azc Almere - De Meergaard; 2001

5. Gerritsen AA, Bramsen I, Devillé W, Willigen LH van, Hovens JE, Ploeg HM van der. Physical and mental health of Afghan, Iranian and Somali asylum seekers and refugees living in the Netherlands. Soc Psychiatry Psychiatr Epidemiol. 2006;41(1):18-26.

6. Merry L, Pelaez S, Edwards NC. Refugees, asylum-seekers and undocumented migrants and the experience of parenthood: a synthesis of the qualitative literature. Glob Health. 2017;13(1):75.

7. Flegar V. Quickscan: zorg voor asielzoekerskinderen in Nederland. Den Haag: Werkgroep kind in azc;2016.

8. Vlasblom E, Sleuwen BE van, Beltman M, Rijnders MEB. Evaluatie van centering parenting in Nederland. Leiden: TNO; 2016.

9. Resnicow K, Baranowski T, Ahluwalia JS, Braithwaite RL. Cultural sensitivity in public health: defined and demystified. Ethn Dis. 1999;9(1):10-21.

10. Eldredge LKB, Markham CM, Ruiter RA, Fernández ME, Kok G, Parcel GS. Planning health promotion programs: an intervention mapping approach. San Francisco: John Wiley;2016.

11. Pharos. Cultuur sensitieve zorg. https://www.pharos. $\mathrm{nl} /$ sensitieve-zorg-voor-gezinnen-in-de-eerste-1000dagen/cultuursensitieve-zorg/. Hoofddorp: Pharos, 2019. Geraadpleegd op: 26 mei 2020.

12. Bruinsma W, Konijn C. Antwoord op veelgestelde vragen over effectiviteit. Jeugd En Co Kennis. 2008;2(3):17-23.

13. Bloomfield J, Rising SS. CenteringParenting: an innovative dyad model for group mother-infant care. J Midwifery Womens Health. 2013;58(6):683-9.

14. Lachman JM, Kelly J, Cluver L, Ward CL, Hutchings J, Gardner F. Process evaluation of a parenting program for low-income families in South Africa. Res Soc Work Pract. 2018;28(2):188-202.

15. Baumann AA, Powell BJ, Kohl PL, et al. Cultural adaptation and implementation of evidence-based parent-training: a systematic review and critique of guiding evidence. Child Youth Serv Rev. 2015;53:113-20. 